Journal of Social Sciences (COES\&RJ-JSS)

ISSN (E): 2305-9249 ISSN (P): 2305-9494

Publisher: Centre of Excellence for Scientific \& Research Journalism, COES\&RJ LLC

Online Publication Date: $\mathbf{1}^{\text {st }}$ October 2020

Online Issue: Volume 9, Number 4, October 2020

https://doi.org/10.25255/jss.2020.9.4.1358.1371

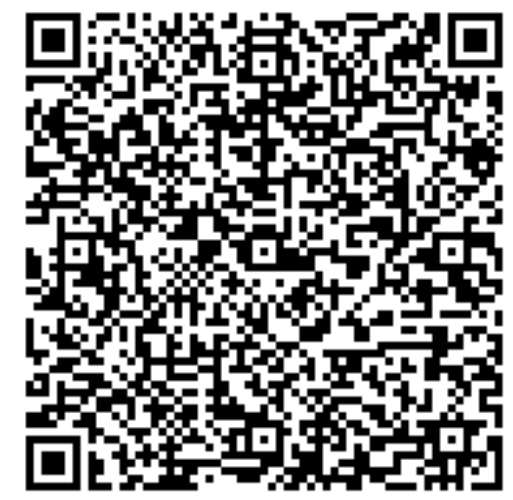

\title{
Al-Farabi between Philosophy and Religion
}

and the Influence by Plotinus

Dr. Maha Alsamhori

PhD: Philosophy

Assistant Professor, Faculty of Arts, University of Jordan, Amman, Jordan

malsamhori@gmail.com

Dr. Mahmoud Bani Domi

PhD: Philosophy, adwaar@yahoo.com

Dr. Mona Seine

PhD: Sociology

Assistant Professor, Faculty of Arts, University of Jordan, Amman, Jordan

m.seine@ju.edu.jo

Dr. Manal Fathi Anabtawi

PhD: Disaster and Crises Management

Assistant Professor, Faculty of Arts, University of Jordan, Amman, Jordan

Dr.manal.anabtawi@gmail.com

Dr. Talal Al-Qdah

University of Jordan, Amman, Jordan, talal_qdah@yahoo.com

\section{Abstract:}

This study aims at finding to which extent Farabi's philosophy was influenced by Neoplatonism, especially in terms of the topics presented and the way they were addressed. This comes in the framework of knowing to which level both Farabi and Plotinus influenced, and were influenced by religion in the matter of: The One, The Intellect and The Soul on one hand, the knowledge, reconciliation between religion and philosophy, on the other. The study also examined the similar circumstances that surrounded Plotinus and Al-Farabi, which may have

\footnotetext{
This work is licensed under a Creative Commons Attribution 4.0 International License.
} 
been a major reason for presenting and raising similar topics. The study concluded that the philosophical context is derived from the events and circumstances that philosophers live through, and that the issues raised by both philosophers show influence on and by religion. Most importantly there is no way to either deny or affirm what they agreed or disagreed upon, except for their aim; for the philosophy they both presented asserted that they sought happiness.

\section{Key words:}

Al -Farabi, Islamic philosophy, Platonism, Plotinus, Religion

\section{Citation:}

Alsamhori, Maha; Domi, Mahmoud Bani; Seine, Mona; Anabtawi, Manal Fathi; Al-Qdah, Talal (2020); Al-Farabi between Philosophy and Religion and the Influence by Plotinus; Journal of Social Sciences (COES\&RJ-JSS), Vol.9, No.4, pp:1358-1371; https://doi.org/10.25255/jss.2020.9.4.1358.1371.

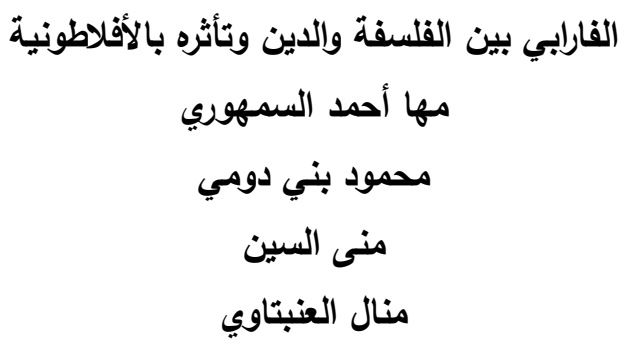

الملخص

تسعى الدراسة إلى البحث في مدى تأثز فلسفة الفارابي بالأفلوطينية المحدثة وخاصة من

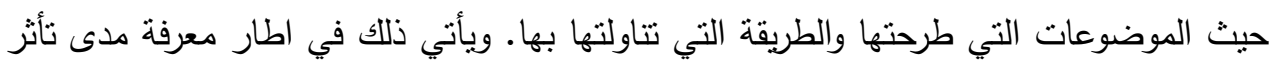

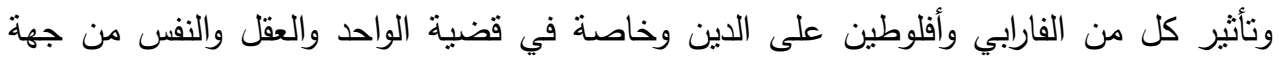

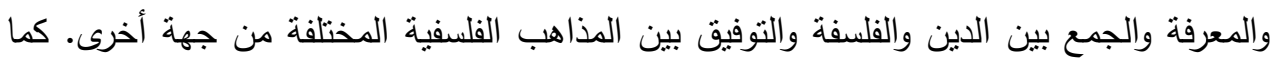
وققت الدراسة على الظروف المنشابهة التي أحاطت بأفلوطين والفارابي التي ربما كانت سيبًا رئيسيًا في تتاول وطرح موضوعات مشتركة. وقد خلصت الدراسة إلى أن السياق الفلسفي وليد سياق الأحداث والظروف التي يمر بها الفيلسوف نفسه. وأن القضايا التي تطرح عند الفئ الفيلسوفان تنبين

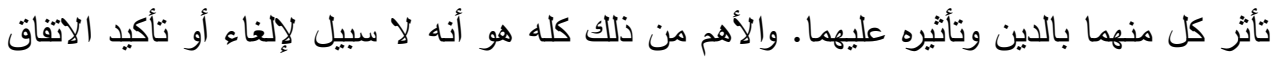

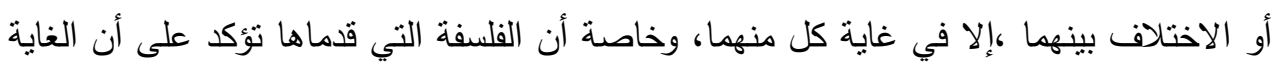
التي كان يصبو كل منهما إليها هي السعادة. الكلمات المفتاحية: الفارابي، الفلسفةالإسلامية، الأفلوطينية، أفلوطين، الدين. 
تتفرد فلسفة الفارابي (توفي 339 هـ/950م) وهو مؤسس الفلسفة المشائيّة الإنلاميّة،

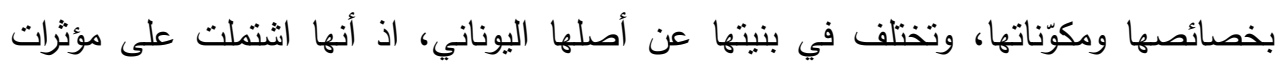

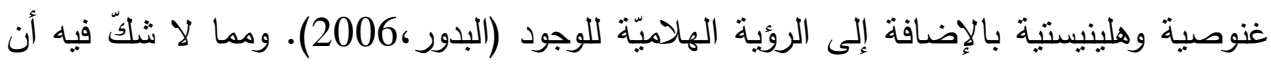

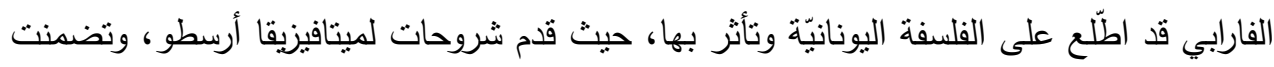

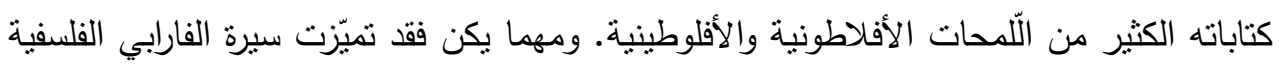

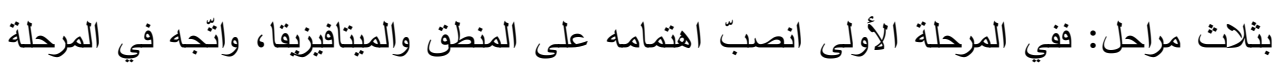

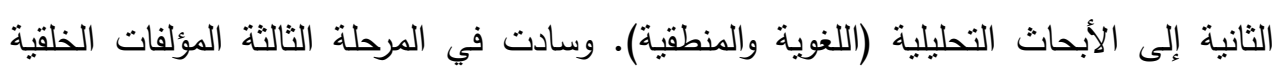
والسياسية (خليفات،2004) .

\section{المصادر الأفلوطينية في فلسفة الفارابي}

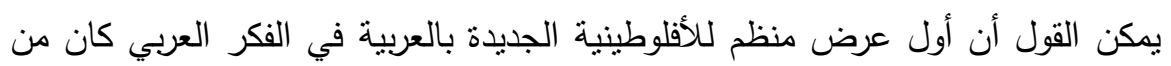

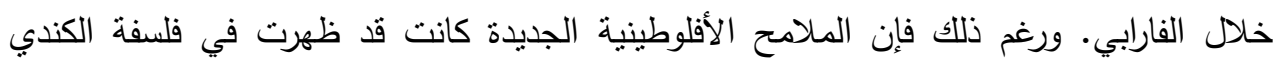

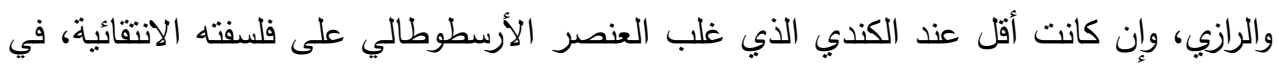

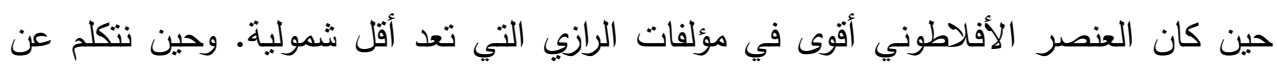

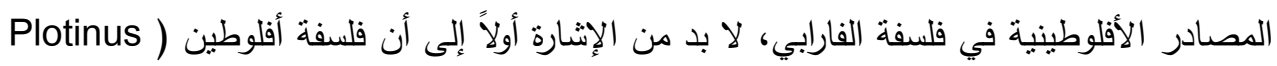

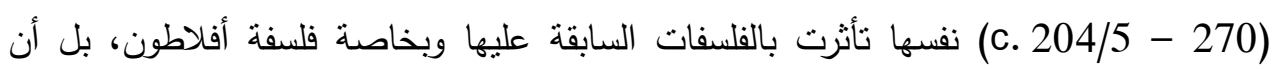

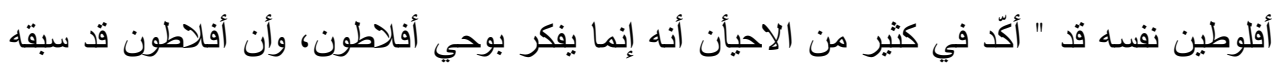

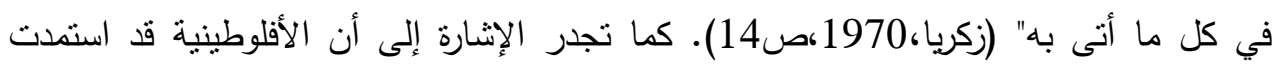

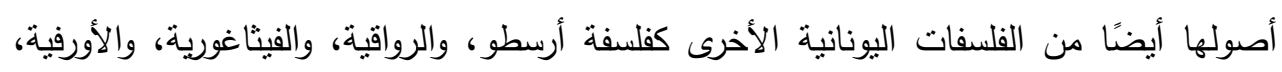

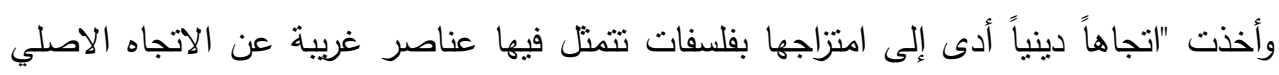

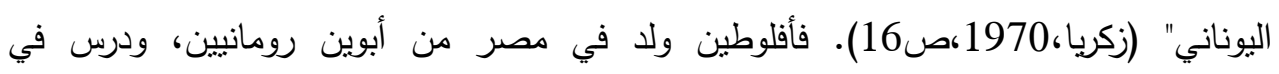

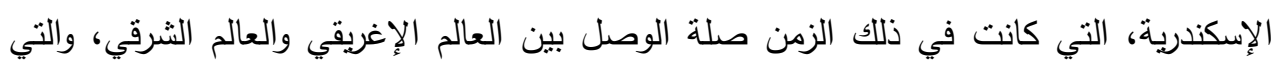

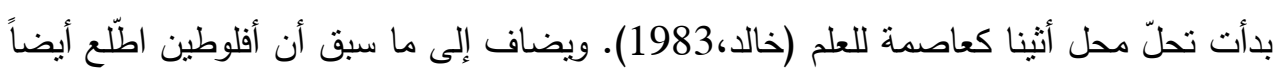

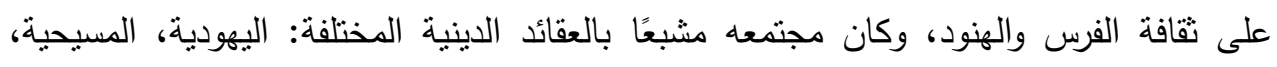

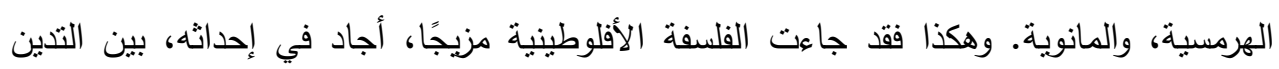

$$
\text { والفلسفة (خالد،1983،صنئ18 - 21). }
$$

وعند البحث في المصادر الأفلوطينية في فلسفة الفارابي يجب عدم الحديث عن "أصل"

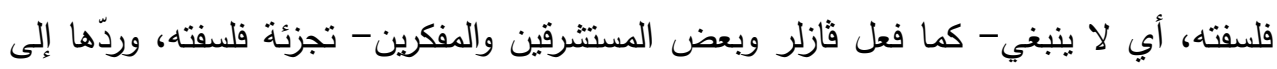

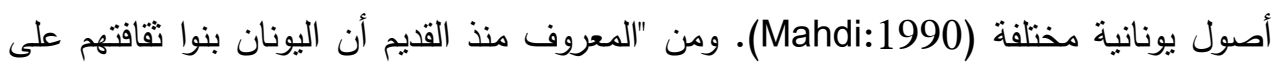


فلك الكلدانيين والبابليين وعلوم المصريين القدماء... ويجب أن لا ننسى أن طاليس، "مؤسس" العلم والفلسفة اليونانيين، وأفلاطون الذي بلغ بالفلسفة أوجها، قد زارا مصر ، وكأن لهما معها اتصال ثقافي" (الجابري،2006،ص 84). وبالتالي فإن الفلسفة وعلوم الأوائل نتقلت كثيراً عبر الزمان والمكان، وكانت في تجدّد دائم من خلال امتزاج الثقافات والحضارات المختلفة. فالحضارات بكل مكوناتها ليست مستقلة عن العالم الخارجي، لا في الزمان ولا في المكان،وهذا التجدد سواء كان ماديًا أو معنويًا فهو نتاج التأثر بالسابقين والتأثير على اللّاحقين. وما يهةٌ هنا هو التأثز والتأثير في تطور الفكر وخاصة المذاهب الفلسفية.

فلسفة أفلوطين

لبيان مدى تأثز الفارابي بالأفلوطينية وخاصة في ربطه بين الفلسفة والدين، لا بد من استعراض فلسفة أفلوطين وخاصة فيما يتعلق منها بالنفس والمعرفة والألوهية. فمن المعروف أن بأن أفلوطين قد تأثز بأفلاطون، كما تأثز أيضا بنومينوس الذي نزّه الله عن كل شيء حتى الخلق. وكذلك بأستاذه أمونيوس ساكاس السكندري، الذي روى فرفوريوس عنه "أنه ولا مسيحيًا، ولكنه ارتذّ بـ إلى الوثثية عندما تفرّغ إلى الفلسفة" (زكريا،1970،ص14). والمعروف عن أمونيوس محاولته

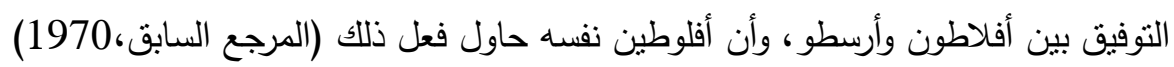
تقوم فلسفة أفلوطين في الجزء الأكبر منها على فكرة الألوهية أو فكرة "الله" أو العالم المعقول، حيث ينتقل الإنسان من العالم المعقول إلى العالم المحسوس الذي يحاول منه أن يرتفع ثانية إلى الوحدة الأولى(بدوي،1959). وهكذا فإن الغاية من فلسفته هي الإرشاد إلى الطريق الذي به يصل الإنسان إلى إفناء الذات في الوحدة الإلهية وإلى إيجاد التجربة الروحية التي يسنطيع الإنسان بواسطتها أن يتّحد بالواحد. ولذا فإننا نجد أن فلسفته تتأسس على الوجدان والإنه والتجربة الذوقية الصوفية والكثفية. وهذا يعني تأثره بالتجربة الدينية التي تعدّ نقطة البدء ونقطة الانتهاء في فلسفته. وتعدّ هذه النزعة شرقية بامتياز مهما ظهر عليها من نأثز بالفلسفة اليونانية؛ وهذا يتّضح بتثبّع الأفكار وانتشارها في بيئة ساد فيها أفكار من نفس جنس أفكار أفلوطين كفكرة الملائكة أو بأ فئية الوسطاء أو العقول المتوسطة، ثم فكرة الصدور خاصة التي سادت في تلاك التقافات منذ أربعة آلاف سنة ونيف في كل من: شريعة (أوركاجينا)، وشريعة (حمورابي)، وفي أسطورة الخلق البابلية (اينوما ايليش). ولذا فقد بنى أفلوطين فلسفته على عالمين الأول هو المعقول ويشمل الله، العقل،

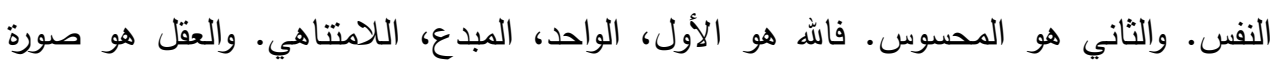
الأشياء الموجودة. والنفس هي ما به يتم تحقق الصور في المحسوسات، أو هي قوة تكون في هون الواقع وسطًا بين فعل الأول وتحقق العقل بوصفه صورًا. وهذه النفس هي آخر الكائنات الموجودة في العالم المعقول، وأول الكائنات الموجودة في العالم المحسوس (بدوي، 1959). 


\section{Al-Farabi between Philosophy and Religion and the Influence by Plotinus}

يعتبر أفلوطين فيلسوفًا ومتصوفًا في آن واحد. وهو في سعيه إلى فهم الحقيقة، يحاول أن

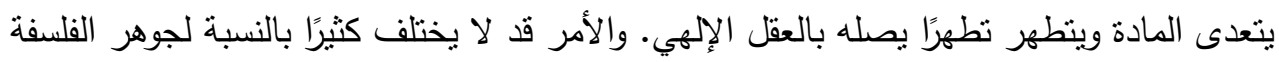

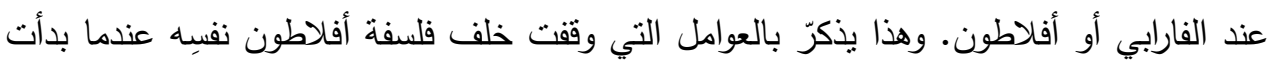
المعنقدات الدينية بالتهافت بعد سلسة الحروب البلبونيسية التي خلقت فوضى فكرية حملت على

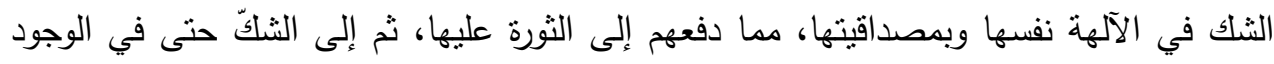

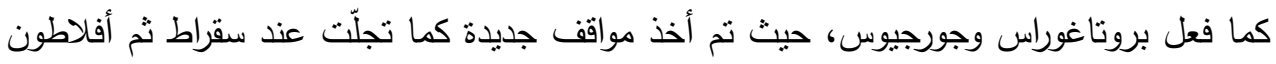

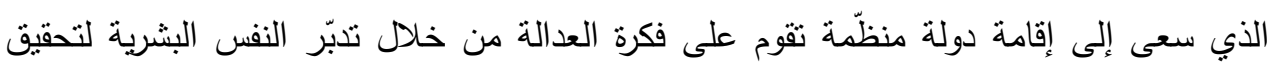

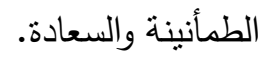

\section{فلسفة الفارابي}

لقد تأثرت فلسفة الفارابي أيضًا باضطرابات فكرية وسياسية عندما كانت الخلافة الإسلامية

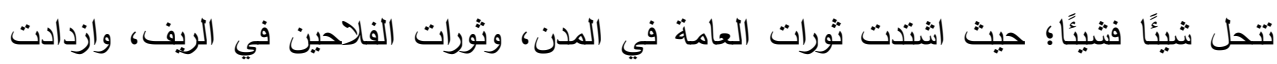

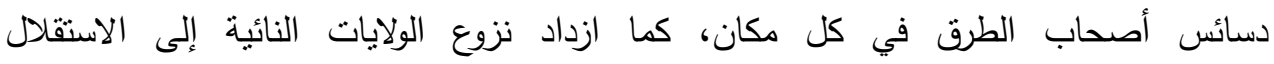

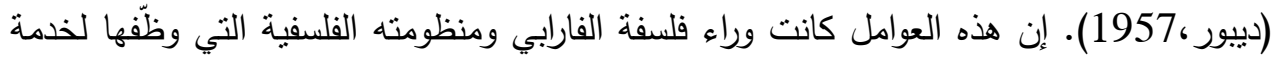

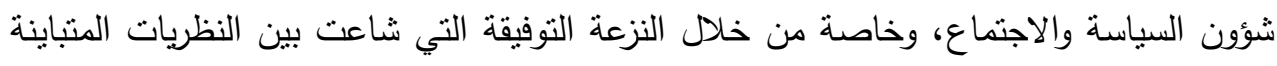

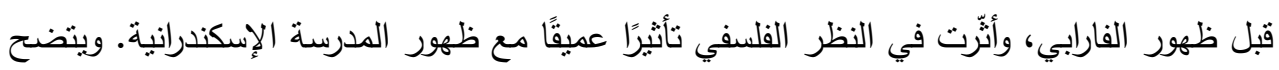

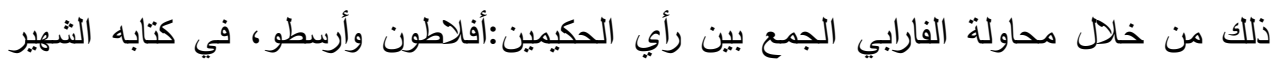

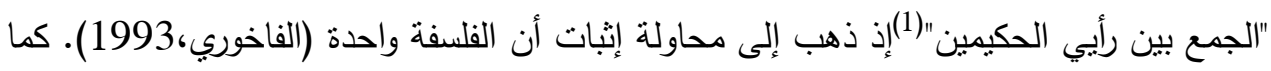

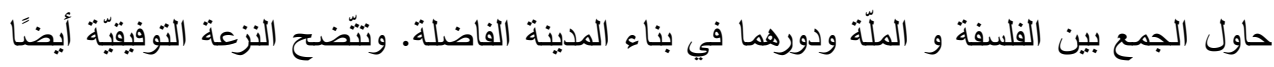

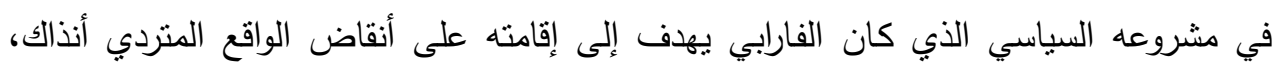
وإقامة نظام حكم عادل.

وبالنسبة للفارابي فإن هذا المشروع، لا يمكن فهمه ولا استيعابه إلا من خلال فهم نظرية الوجود، وفيض الموجودات وصدور النفس الإنسانية، إلى جانب معرفة درجات العقل وحصول

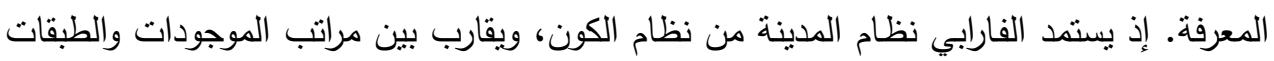

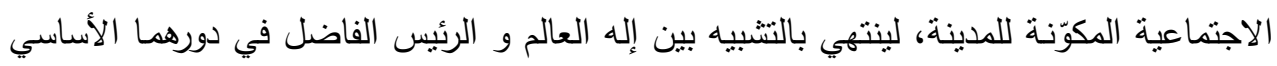

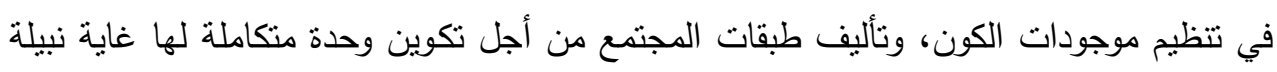

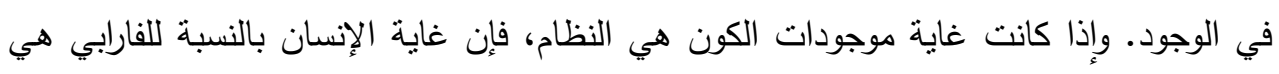

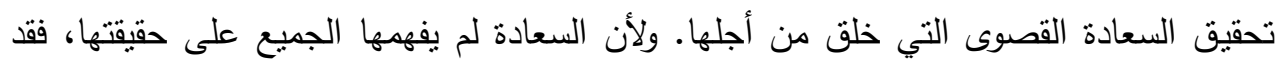

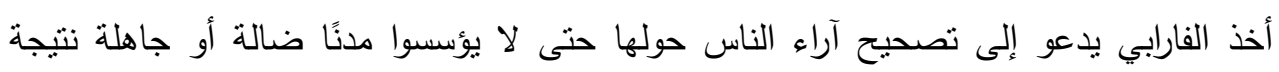

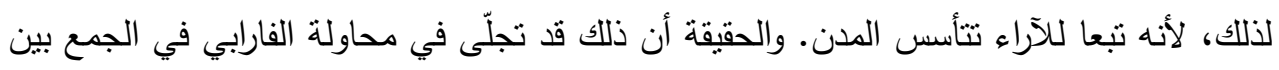


الفيلسوف و النبي، إذ بيّن مدى اتفاقهما و قدرتهما على قيادة الأمم (بجاوب وبلعزوقي،2004).

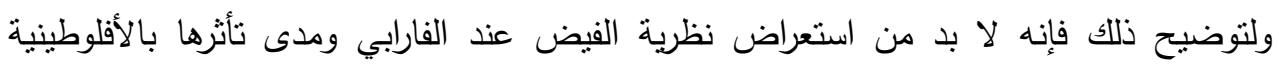

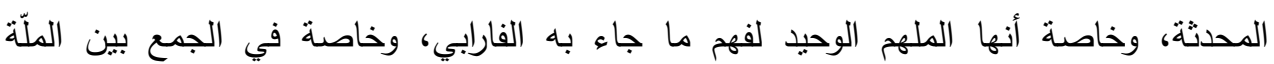
والفلسفة.

\section{نظرية الفيض}

تأثر الفارابي عند صياغة نظريته في الفيض بفكرة الفيض الأفلوطينية مع الاختلاف في التفاصيل،وفي التوظيف. لقد كانت نظرية الفيض الفارابية تمهيدًا لمنظومته السياسية والاجتماعية

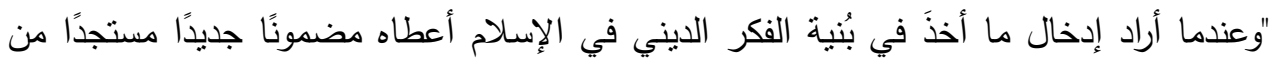

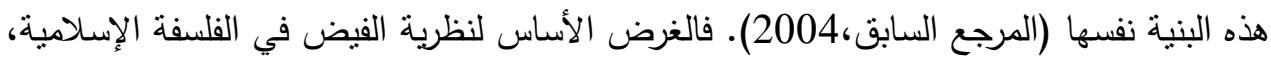

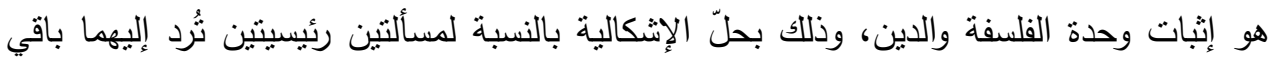

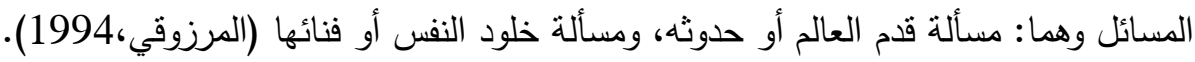
كانت محاولة الفارابي هذه في التوفيق بين الفلسفة والدين ضرورية، الفئ، حيث أن أن بناء مدينته

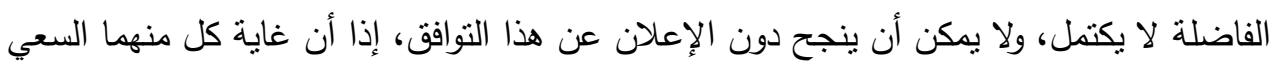

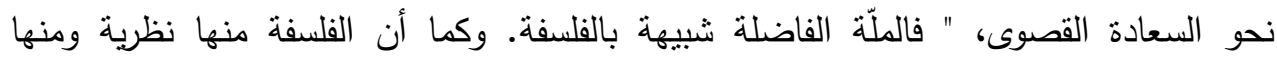

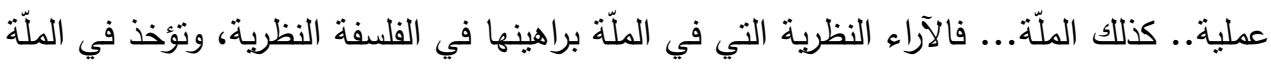

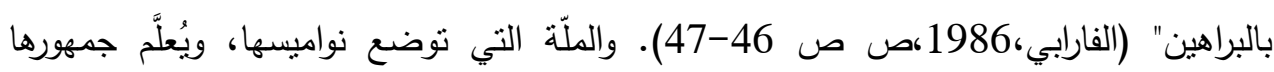

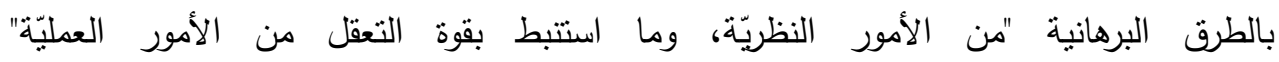

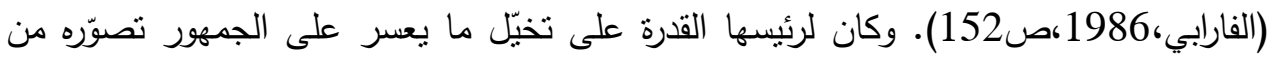

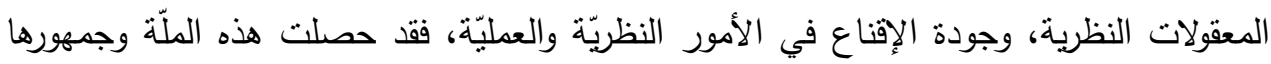

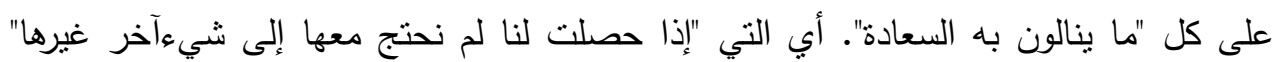

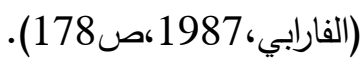

\section{الواحد والعقل والروح والنفس عند أفلوطين والفارابي}

تذهب نظرية الفيض إلى "القول بأن الهه قد أبدع الكون من لا شيء، كما يُعلَّمَ الدين، وبأن العالم أزلي كما تريد الفلسفة (اليازجي، 1965). فالصدور فعل طبيعي ضروري لا يوصف بأنه

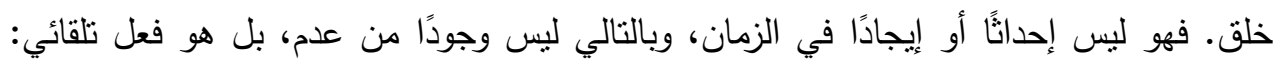

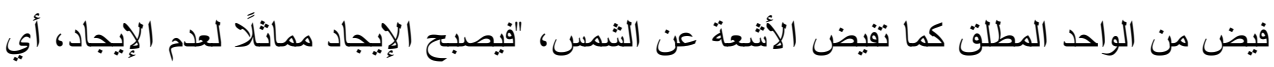

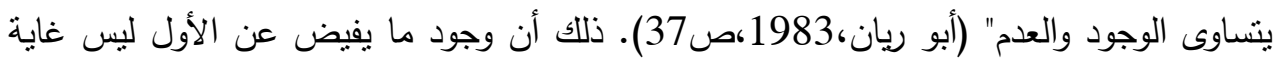




\section{Al-Farabi between Philosophy and Religion and the Influence by Plotinus}

وجوده، "ولا على أنه يفيده كمالاً...... فلذلك وجوده الذي به فاض الوجود إلى غيره هو في

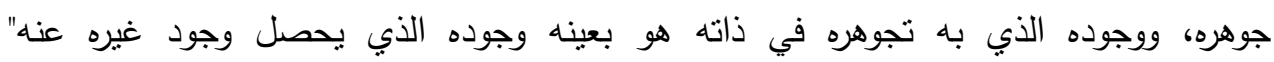

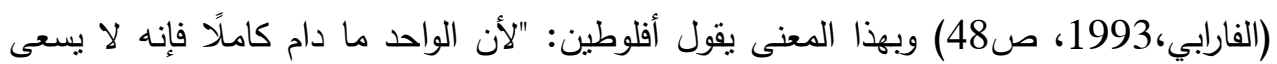
وراء شيء، ولا يملك شينًا، ولا يحتاج إلى شيء فإنه يفيض، وفيضانه هو الذي يبدع شينًا يختلف

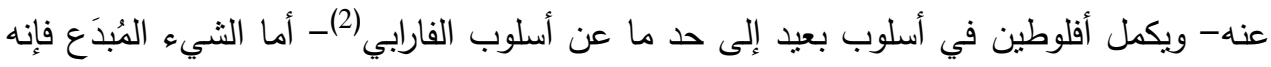

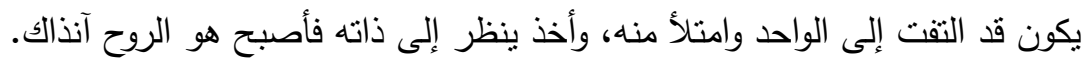

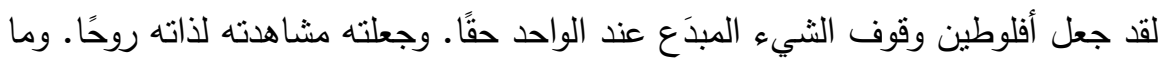

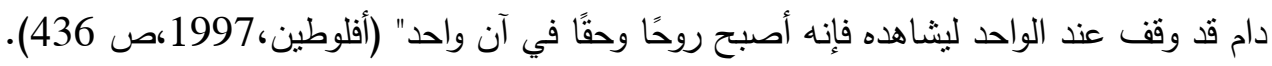

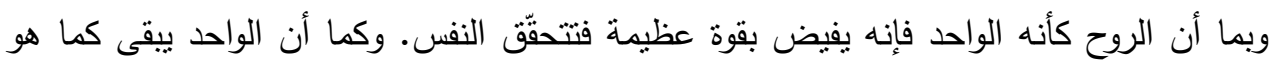

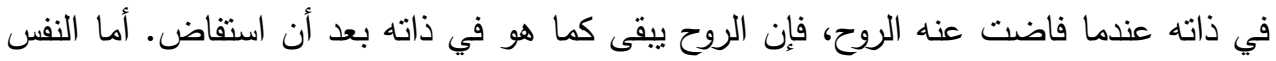

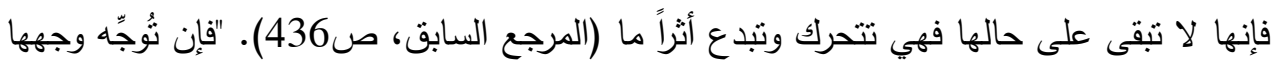

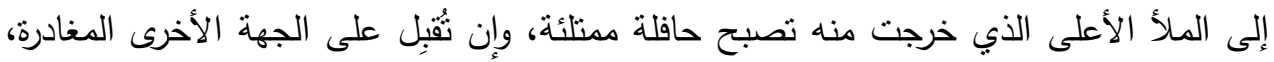

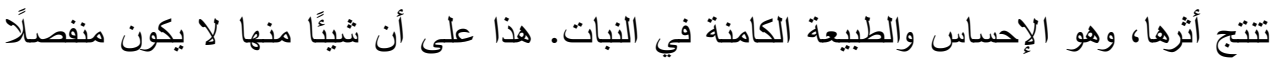

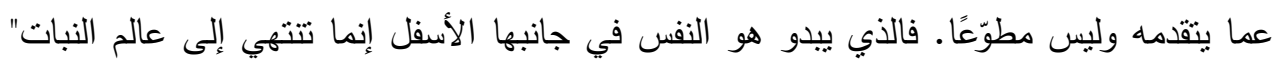

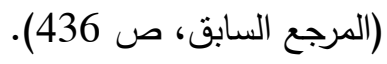

تتسلسلُ النفس التي تنقى متصلة بالواحد عن طريق الروح، في رأي أفلوطين، إلى أن

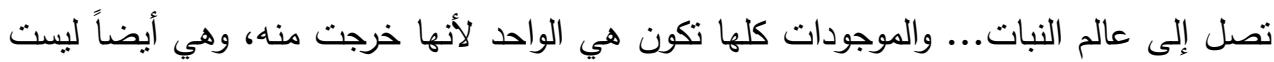

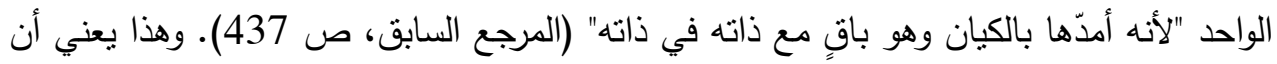

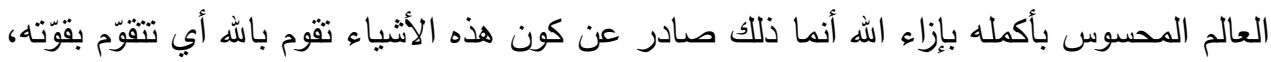

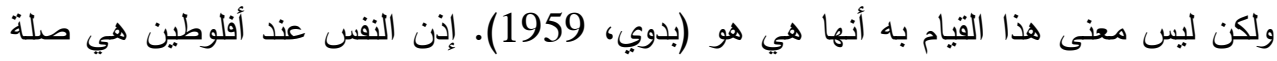

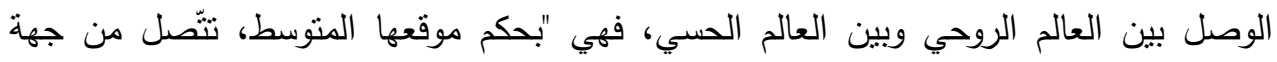

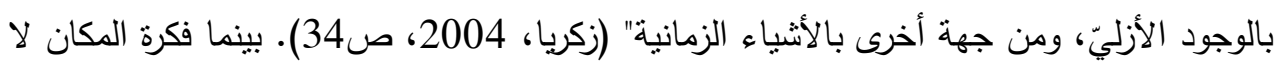
تتطبق عليها كما لا تتطبق على الواحد والروح.

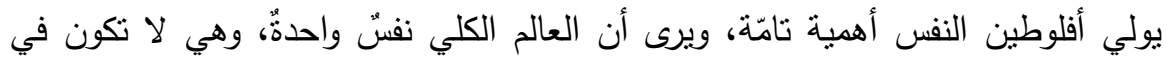

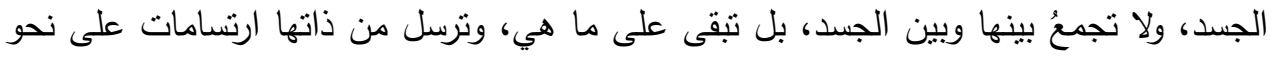

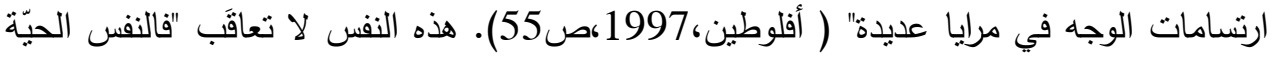

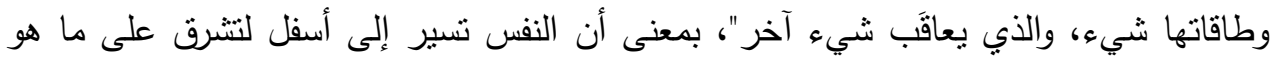

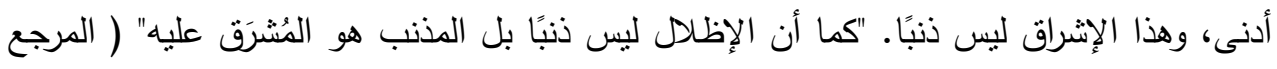


السابق، ص58). وهكذا لا يوجد عقاب لا للنفس ولا لمادتها، إذ المادة تتعدم أصلًا بعد انسحاب النفس منها.

ومهها كان التأثثر أو طبيعته، فإن الفارابي يسير عكس هذا الاتجاه ليؤكد مكانة العقل

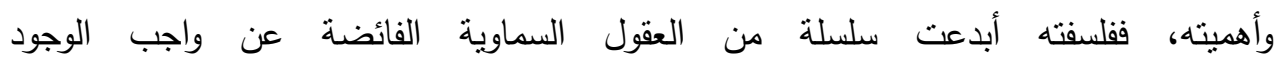

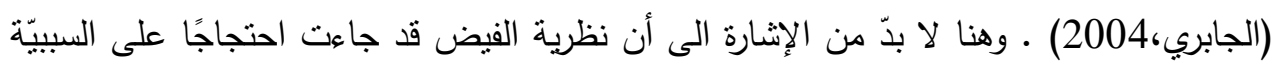

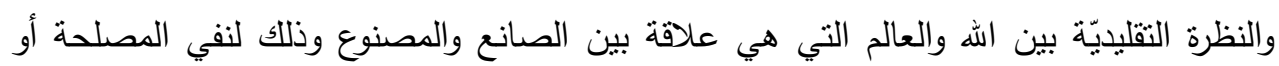

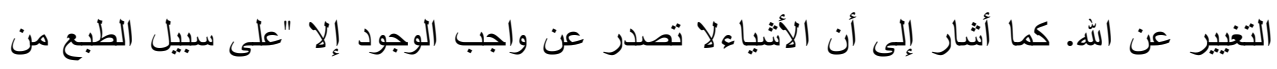

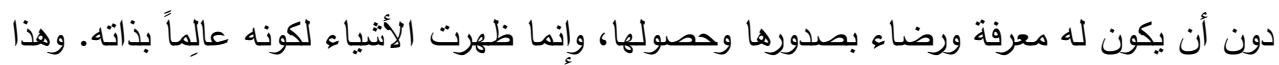

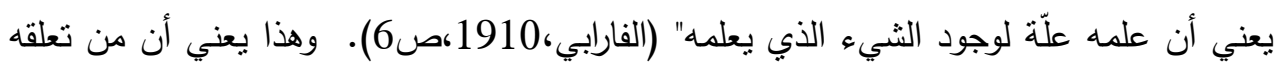

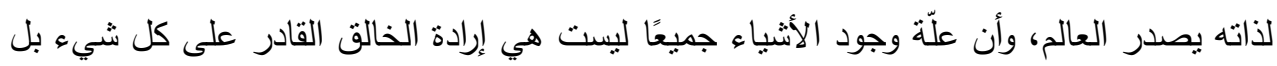

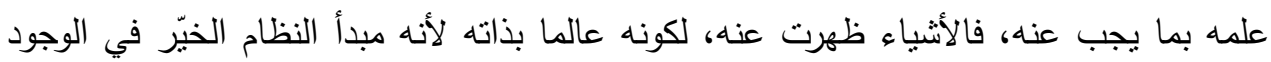

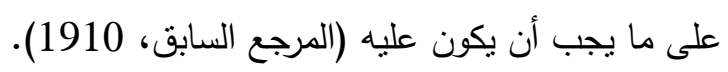

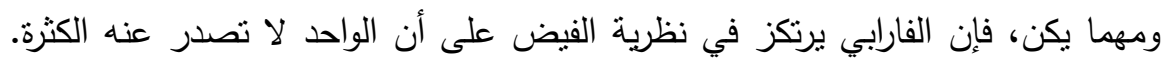

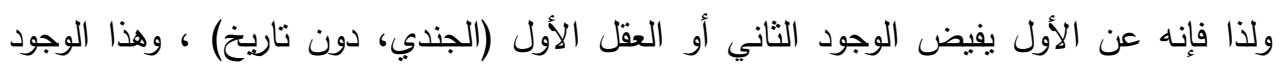

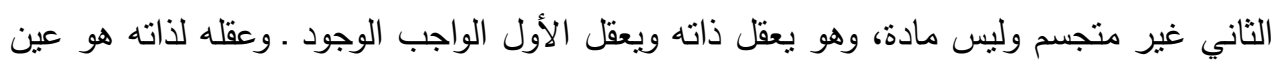
ذاته، وهو بما بعقل ذاته التي تخصه وبما هو متجوهر بها بلزم عنه وجود السماء الأولى، وهو بما

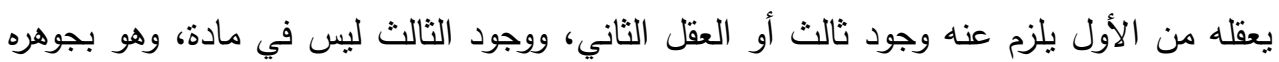
عقل، يعقل ذاته ويعقل الأول، وهو بما يعقله من الأول يلزم عنه وجود رابع أو العقل الثالث، وهذا

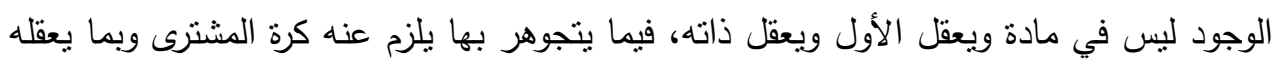
من الأول يصدر عنه وجود خامس، وهكذا يمضي الفارابي مع نظريته في الفيض منأثنرا بأفلفوطين

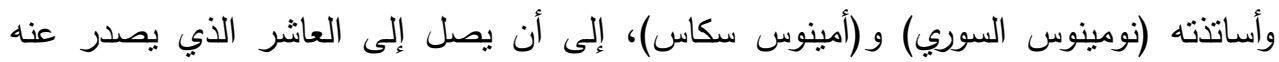

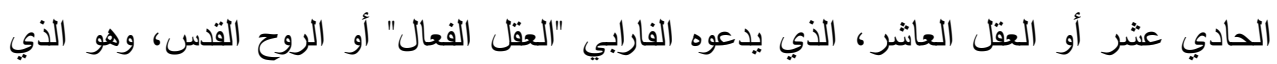
يصل العالم العلوي بالعالم السفلي وهو الذي يسبب وجود الأنفس الجزئيّة والعناصر بمساعدة التراي

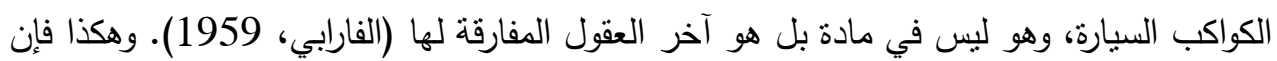

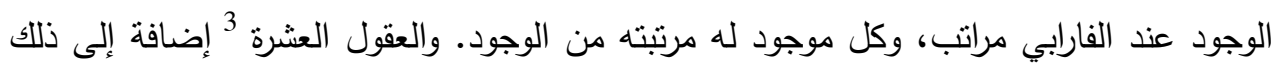

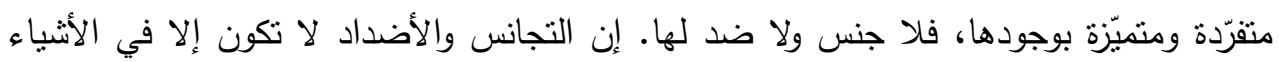

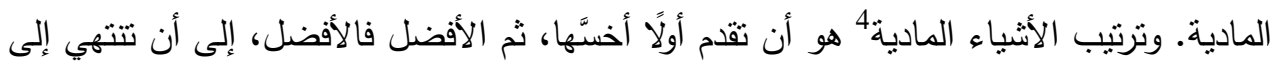

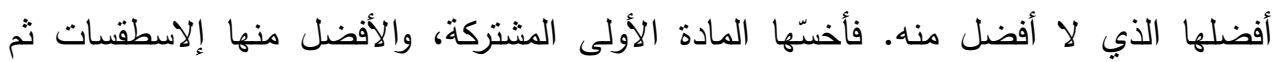


الدعدنية، ثم النبات، ثم الحيوان غير الناطق، ثم الحيوان الناطق. وليس بعد الحيوان الناطق أفضل منه (المرجع السابق، 1959).

نجذُ في فلسفة الفارابي أن الحيوان الناطق هو أعلى الموجودات شأنًا في التسلسل

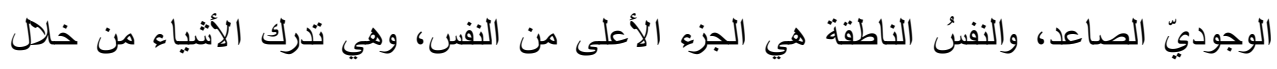

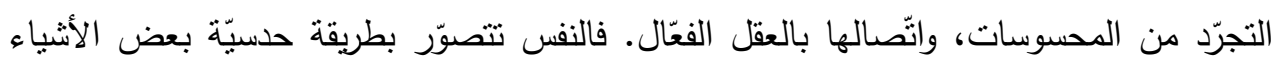

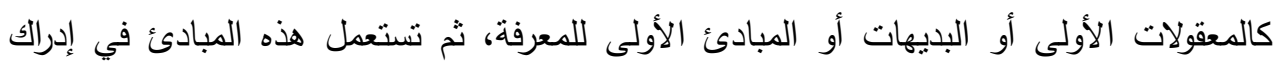

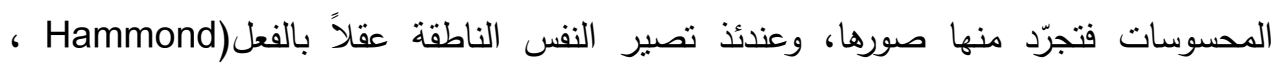
1947). والذي ينقلها من القوة إلى الفعل هو العقل الفعّال.

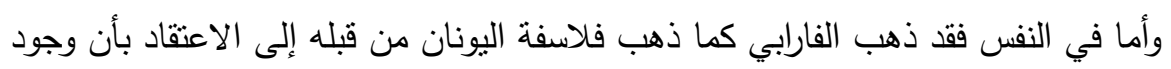

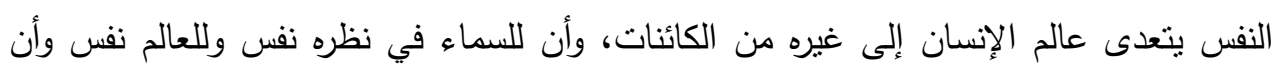

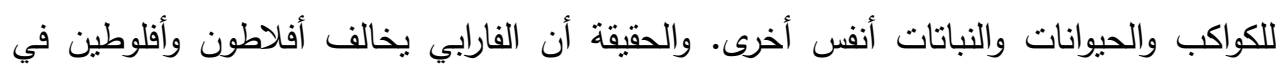

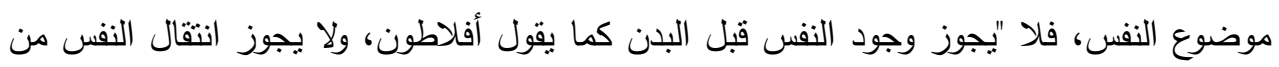

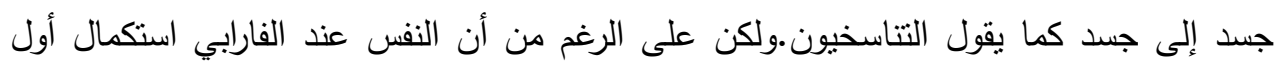

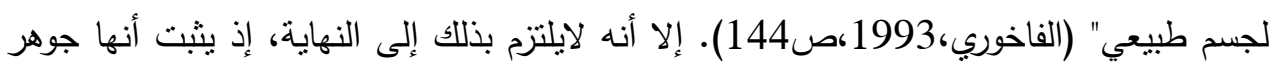

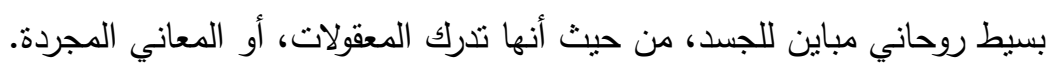

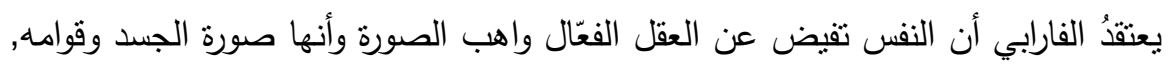

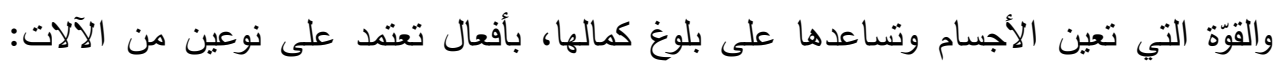

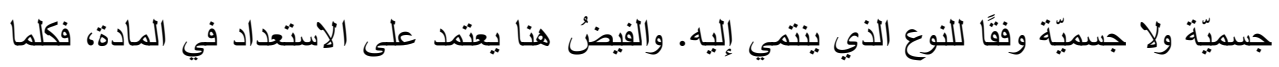

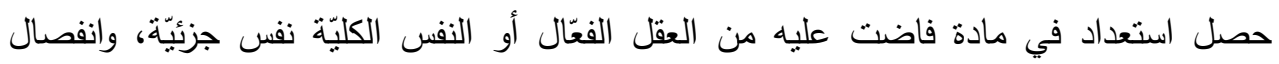

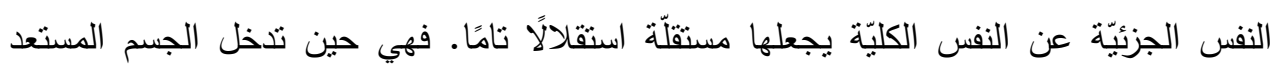

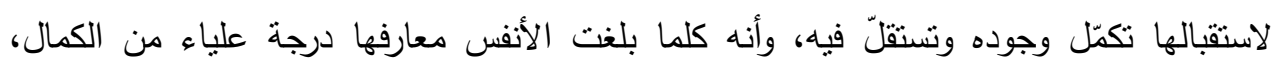

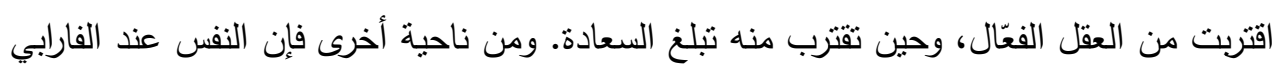

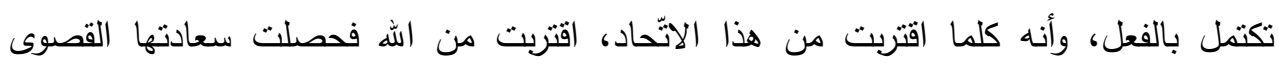

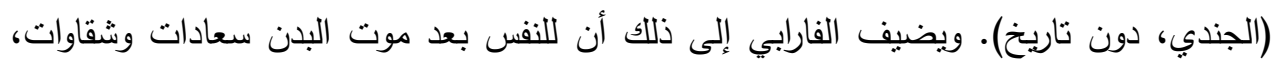

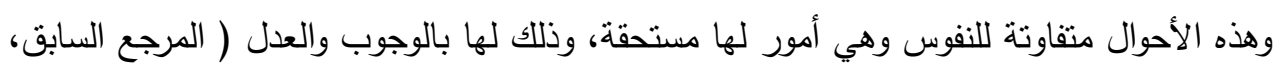

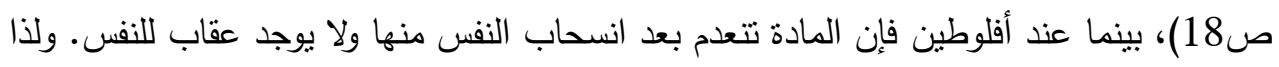

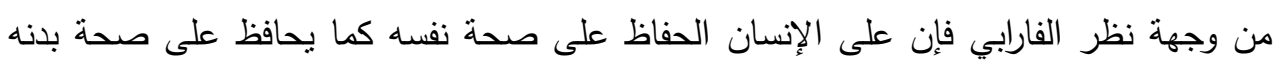

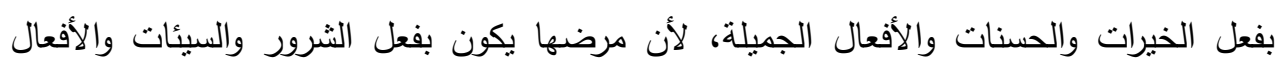

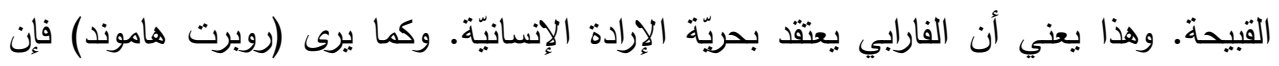


فلسفة الفارابي هنا لم تتأثز بالأفلوطينية المحدثة بربط الثرّ في المادة واعتبار الثرّ موجودًا بالعَضض في العالم (Al Farabi, 1989 ).

تأثر الفارابي بالعرفان الأفلوطيني

قد يبدو نأثر الفارابي بالعرفان الأفلوطيني من خلال المعرفة الإثراقيّة التي وضع أساسها

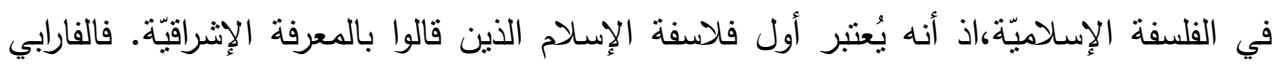

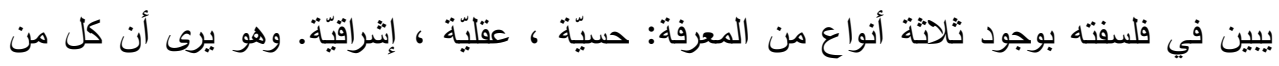

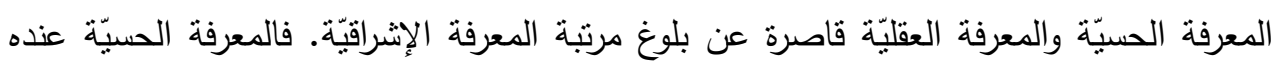

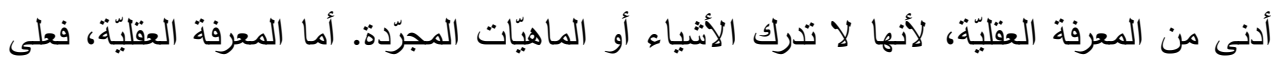

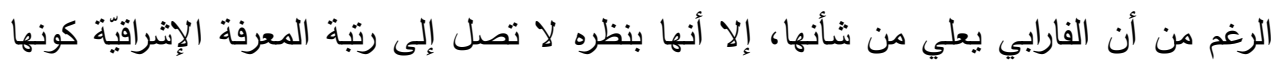

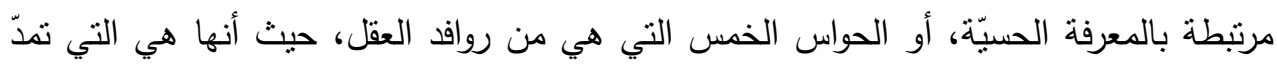

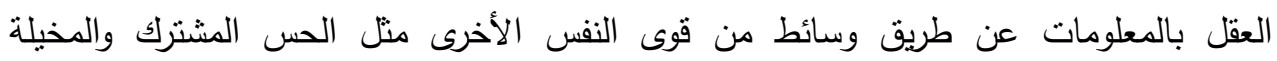

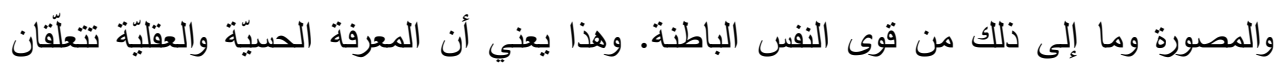

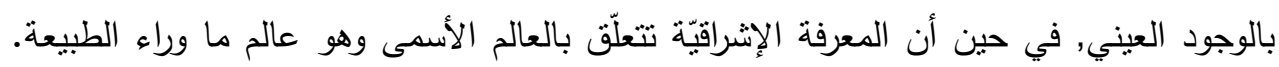

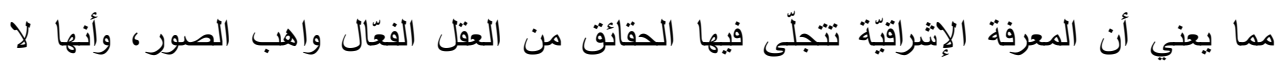

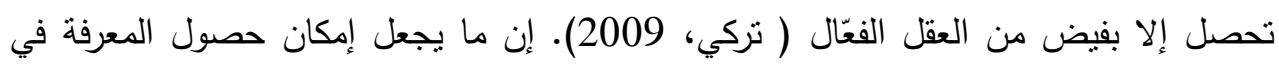

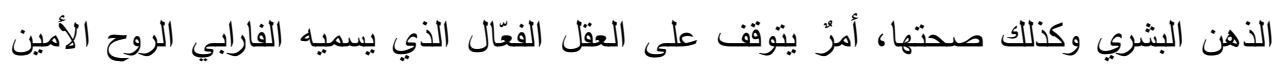

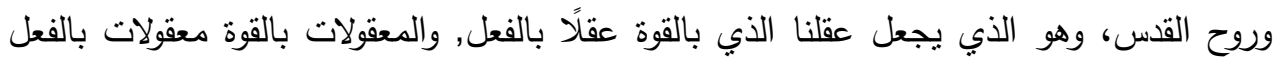

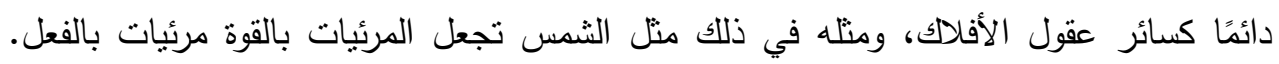

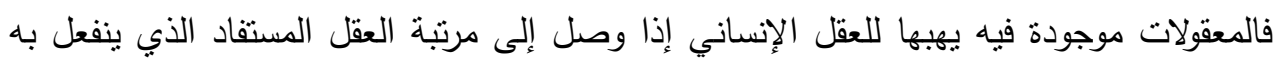

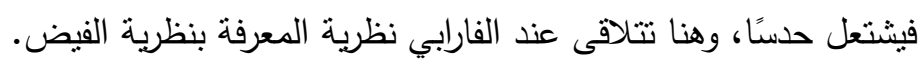

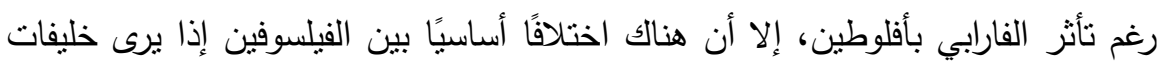

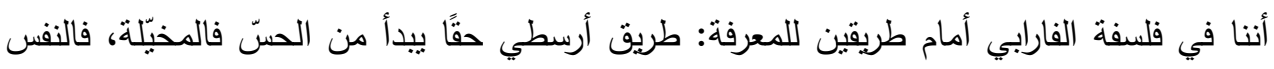

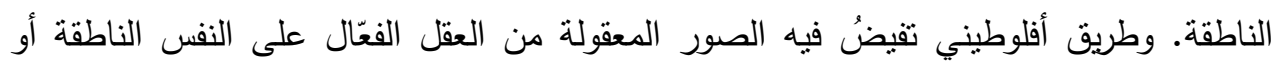

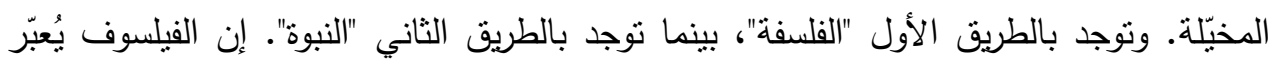

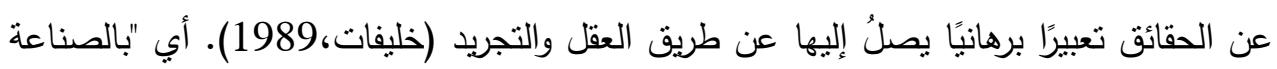

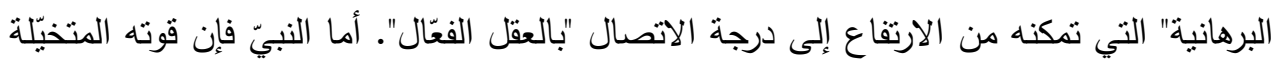

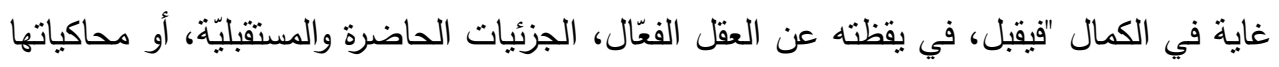




\section{Al-Farabi between Philosophy and Religion and the Influence by Plotinus}

من المحسوسات، ويقبل محاكيات المعقولات المفارقة وسائر الموجودات الثريفة، ويراها. فيكون له

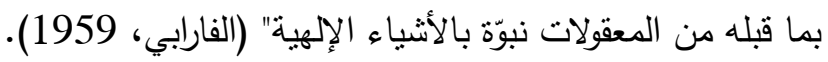

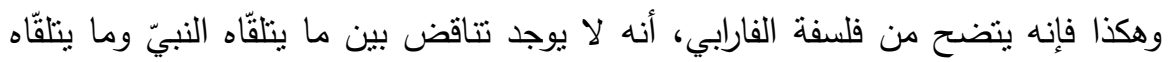
الفيلسوف. وبالتالي "لا تناقض بين الدين والفلسفة إذ هما يعبران عن حقيقة واحدة" (الجابري،

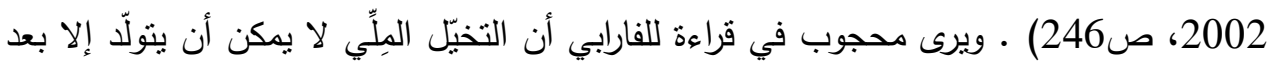

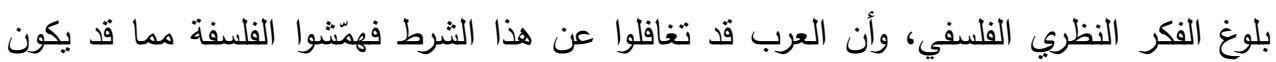
أوقعهم في الضلال عن الحقيقة (محجوب، 1989). ومن هنا فإن انطلاقة الفارابي كانت من أن النبي محمد هو آخر الأنبياء، وبالتالي فإن إنان تحققّ المدينة الفاضلة بعده لا يكون إلا بوجود رئيس لها هو الحكيم الفيلسوف إذ يشترط الفارابي

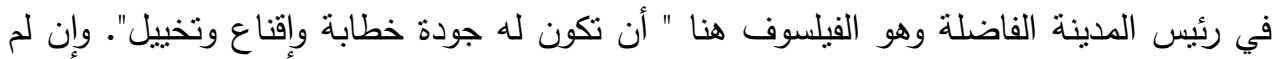

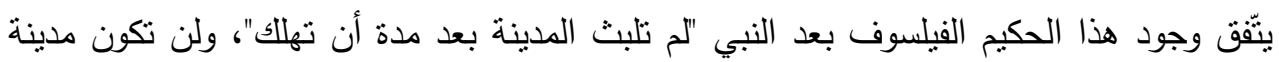
فاضلة تحاكي نظام الكون في تراتبه ترابطه ونظامه. "وهذا الدصير الذي واجهته المدينة الفاضلة

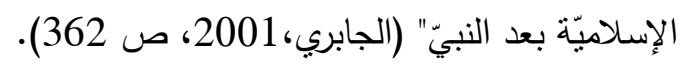

هذا الفهر، وإن اختلف نماما، فإنه من باب التأثر والتأثير، يقابل تأثر وتأثير فلسفة أفلوطين على المسيحية وكيف خدم كل منهما الأخر • إن الواحد المحض الأفلوطيني قائم من ذاته

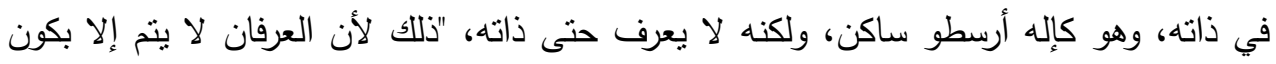

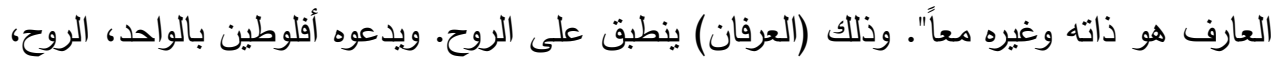

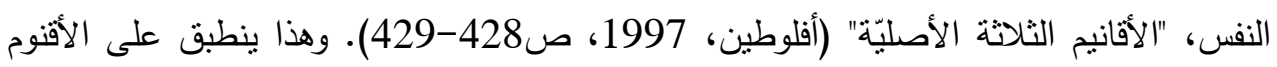

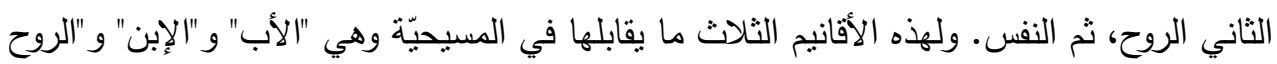

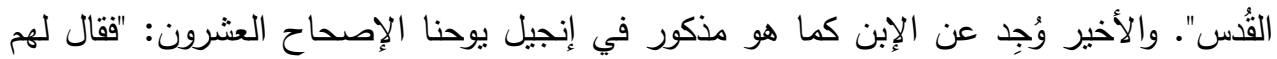

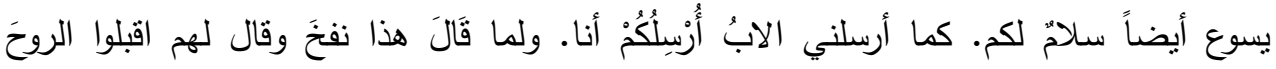

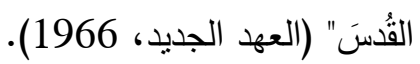

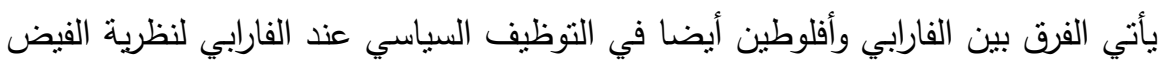

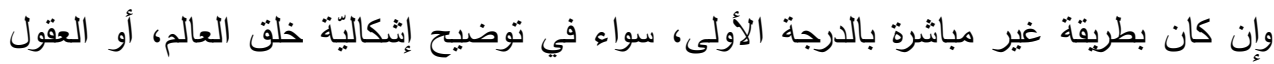

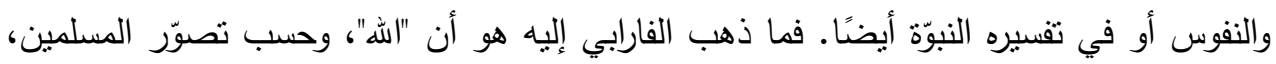

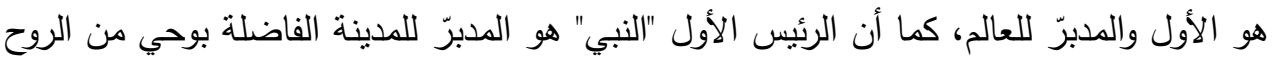

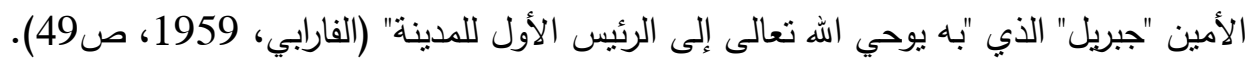

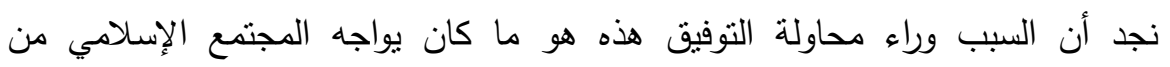

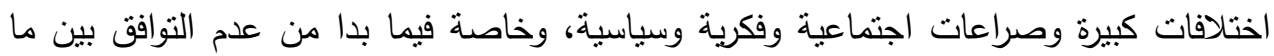


يقرّه العقل وما يعلّمه الدين. وقد تصدى الفارابي لهذا الإشكال من خلال التوفيق بين الفيلسوف الذي يمثل الفلسفة والنبيّ الذي يمثل الدين. فجعل مدينته الفاضلة مدينة يرأسها النبيّ أو الفيلسوف إذ أنه لا فرق في النتيجة بين الرئاستين.

الخلاصة :

سلطت الدراسة الضوء على مدى تأثز فلسفة الفارابي بالأفلوطينية المحدثة وخاصة من حيث الموضوعات التي طرحتها والطريقة التي تتاولتها بها. كما سلطت الضوء على الظروف المتشابهة التي أحاطت بأفلوطين والفارابي التي ربما كانت سببًا رئيسيًا في تتاول وطرح نفس الموضوعات. وقد بيّنت الدراسة مدى تأثز كل من الفيلسوفين بالدين وتأثثرهم عليه، وخاصة في مسائل العقل والنفس والمعرفة والجمع بين الدين والفلسفة من ناحية. وترى الدراسة من خلا الارتباط بين الفارابي وأفلوطين أن السياق الفلسفي كان وليد الأحداث والظروف التي تمر بها الدولة. وأن القضايا التي تطرح، منتابهة من حيث الروئا والهدف ، وأن كل منهما تأتّرّ بالدين وأثّر عليه. والأهم من ذلك كلّه هو أن لا سبيل لإلغاء أو التأكيد على الاثّاق أو الاختلاف بينهما

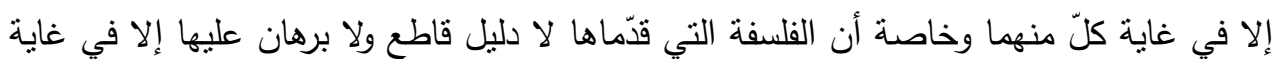
السعادة التي كان يصبو كل منهما إليها، مما يعني أنها فلسفة ماورائية بامتياز • ومهما يكن فإنه، وإن اختلفت المقدمات أو النتائج عند كل منهما إلا أننا نرى أن دعوة الفلسفة أو الدين كانت على سبيل السعادة وليس أكثر من ذللك، لأن السعادة هي الغاية القصوى.

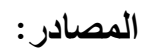

يسوع المسيح، العهد الجديد (1966)، جمعية الكتاب المقد في الثرق الأدنى ، بيروت. - الفارابي، أبو نصر(1959) ، آراء أهل المدينة الفاضلة، تحقيق ألبير نصري نادر، المطبعة الكاثوليكية،ط1، بيروت، لبنان. - الفارابي، أبو نصر(1993)، السياسة المدنية، تحقيق فوزي متري النجار، دار المشرق، بيروت، لبنان. - الفارابي، أبو نصر (1910)، الفلسفة القديمة،عيون المسائل، منشورات وتصحيح المكتبة السلفية، القاهرة. - الفارابي، أبو نصر (1986)، كتاب الحروف، تحقيق محسن مهدي، دار المشرق، المطبعة الكاثوليكية، بيروت، لبنان. 
- الفارابي، أبو نصر (1986)، كتاب الملّة، ونصوص أخرى، تحقيق محسن مهدي، دار المشرق، المطبعة الكاثوليكية، بيروت، لبنان. - الفارابي، أبو نصر (1987)، رسالة التتبيه على سبيل السعادة، تحقيق سحبان خليفات، منشورات

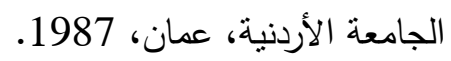
- - أفلوطين (1997)، تاسوعات أفلوطين، ترجمة فريد جبر، ط1، مكتبة لبنان، بيروت.

المراجع:

1. أبو ريان، محمد (1983)، تاريخ الفكر الفلسفي في الإسلام، دار المعرفة الجامعية، الإسكندرية.

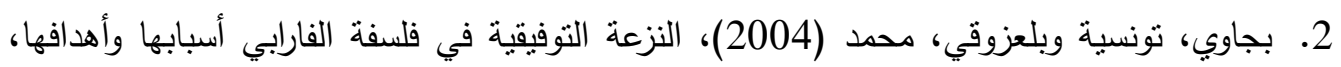
رسالة ماجستير ، جامعة الجزائر ، الجزائر .

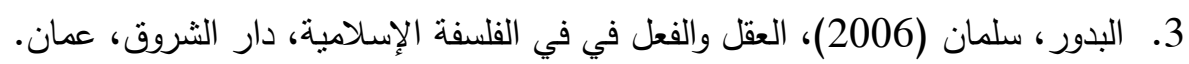
4. بدوي، عبد الرحمن (1959)، خريف الفكر اليوناني، ط3، مكتبة النهضة النصرية، القاهرة.

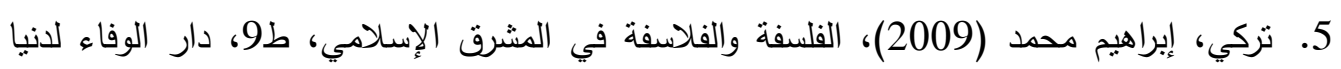
الطباعة والنشر ، الاسكندرية . 6. الجابري، محمد عابد (2001)، العقل الأخلاقي العربي، ط1، مركز دراسات الوحدة العربية، بيروت.

7.

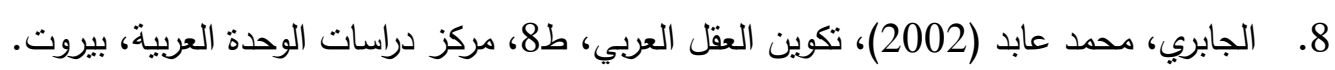

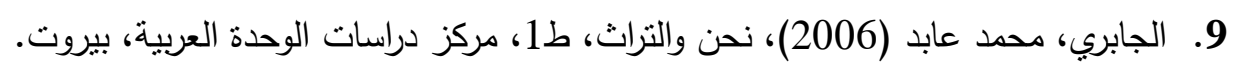

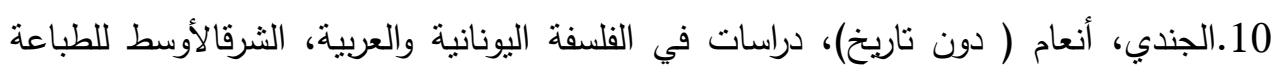

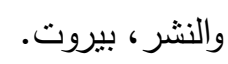

11. خالد، غسان (1983)، أفلوطين رائد الوحدانية، منشورات عويدات، بيروت، باريس. 12. خليفات، سحبان (1989)، المكانة إلابستمولوجية للثعر في فلسفة الفارابي، مجلة أبحان أبحاث

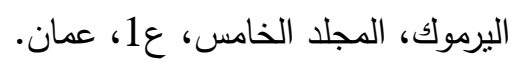
13. خليفات، سحبان (2004)، منهج التحليل اللغوي المنطقي في الفكر العربي الإسلامي، ج2، التهان. منشورات الجامعة الأردنية، عمان. 14. ديبور، ت، ج (1957)، تاريخ الفلسفة في الإسلام، نرجمة محمد عبد الهادي أبو ريدة، ط4، الأل مطبعة لجنة التأليف والترجمة، القاهرة. 
15. زكريا، فؤاد (1970)، مقدمة ترجمة التساعية الرابعة لأفلوطين في النفس، الهيئة المصرية العامة للتأليف والنشر . 16. زكريا، فؤاد (2004)، مدرسة الإسكندرية في الفلسفة والعلم، دار الوفاء للنشر والتوزيع،

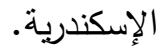
17. الفاخوري، حنا والجر، خليل (1993)، تاريخ الفلسفة العربية، ج2، ط3، دار الجيل، بيروت. 18. محجوب، محمد (1989)، المدينة والخيال: دراسات فارابية، ط1، دار أمية، تونس. 19. المرزوقي، أبو يعرب (1994)، منزلة الكلي في الفلسفة العربية، جامعة نونس الأولى، تونس. 20. اليازجي، كمال وكرم، أنطون (1965) ، أعلام الفلسفة العربية، مكتبة لبنان، بيروت.

\section{References:}

Al-Farabi (1989) Fusul Al-Madani, D. M. Dunlop, Cambridge, The University Press.

Hammond, Robert (1947), The Philosophy of Al-Farabi and Influence of Medieval Thought, the Hobson Book Press, New York.

Mahdi Muhsin (1990), Al-Farabi, Imperfect State, Harvard University.

$$
\text { الهوامش }
$$

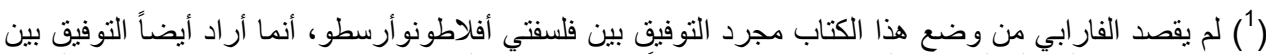

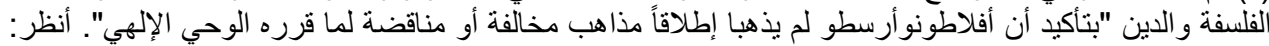

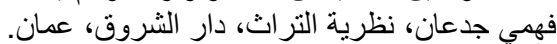
(2) حيث استعان الفارابي أيضاً بعقول أرسطو لتوضيح نظريته في الفيض. 33 في الفصل العاشر من آراء أهل الدينة الفاضلة، جعل الفارابي العقول أحد عثر عقلا، بينما في الفصل الثالث

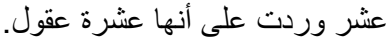
4 ترتيب الموجودات الإلهية تنازليا الأفضل ثم الأنقص فالأنقص، والموجودات المادية تصاعديا الأخس ثم الأفضل 